\title{
APPLICATION OF THE AHP IN ANALYSING DECISION MAKING PROCESS IN PROJECTS: CASE STUDY OF A MAJOR PROJECT DECISION
}

\begin{abstract}
This paper focuses on a special application of the AHP for retrospective analysis of a critical project decision using real data from an infrastructure project. Modelling and analyzing the decision with the AHP were conducted through a case study as part of a comprehensive research on project major decisions. The AHP facilitated analysis of the quality of 'decision making (DM) process' in terms of decision makers' (DMks') biases, their level of compliance and engagement with project objectives and quality of communication during DM. Various features of Comparion Core software were used to facilitate problem analysis. Unlike many applications of the AHP in project management (PM), it was used in its full capacity with a focus on analyzing the DM 'process' rather than a peripheral method to generate input for other DM methods.
\end{abstract}

Keywords: AHP, decision making process, project management, decision analysis.

\section{Introduction}

Decisions are one of the cornerstones of PM due to their direct impact on project success and successful DM needs stakeholder engagement and a fair and transparent process aimed at achieving agreed objectives. While many PM applications of the AHP mainly focus on decision outcome and quantitative analysis of judgments, they rarely provide insights into the DM process quality. Furthermore, many studies use the AHP as a supplement to other methods or only to its partial capacity. This presented case study was a retrospective modelling, resolving and analyzing a major decision in an infrastructure project in the UK solely using the AHP. This was part of the empirical study of an indepth research on projects major decisions based on contemporary approaches to PM and DM. The decision was selection of a refurbishment method among six options for a listed II public building. The AHP provided a structured approach to problem definition and formulation. Capabilities of the method supplemented with features of Comparion Core software, provided an invaluable application of the AHP in analyzing quality of DM 'process', i.e. rationality and biases of DMks' judgments and their awareness of the project big picture. The actual decision was made through a cumbersome, conflictual and time-consuming process but the selected option generally seemed satisfactory to the actual DMks. However, examining the DM process revealed some deficiencies and seemingly avoidable biases, which in fact could affect long-run success of the outcome. 
ISAHP Article: Application of the AHP in in analysis of decision making process in projects: case study of a major project decision - International Symposium of the Analytic Hierarchy Process 2016, London, U.K.

\section{Literature Review}

Significance of decision analysis in PM cannot be underestimated (Virine and Trumper, 2008) but qualitative analysis of DM process in projects remains a gap in literature. The AHP has been known to PM for long though not as far and as well as it deserves to. It has been dominantly used for ranking, prioritizing or selection decisions either solely or as part of other methods (Al-Harbi, 2001; Subramanian and Ramanathan, 2012). Many of such studies are not based on real data from actual DMks; mainly focus on numerical aspects of DM; assume project decisions have 'right' answers besides perceiving DMks as 'perfect and rational' (von Solms, 2011). They normally take positivist and normative approaches to exploring whether the AHP could generate the same outcome as the actual decision (W. Saaty, 2007). Contemporary PM highly criticizes such assumptions and approaches in the context of complex modern projects (e.g., Turner, et al., 2010).

\section{Hypotheses/Objectives}

The overall study aim was improving theoretical and practical deficiencies of current DM models and methods for project tradeoff decisions. The case study aimed at examining capabilities of the AHP as the proposed method for overcoming such deficiencies.

\section{Research Design/Methodology}

Retrospective modeling/analysis of a critical project decision with actual data was the most appropriate approach for an in-depth exploration of an actual DM process and comparing it with an AHP-based model. Core DMKs were interviewed for constructing the AHP hierarchy. Structured data collection was done via pre-designed forms.

\section{Data/Model Analysis}

Results were analyzed for DMk groups with the same expertise. Few unusual judgments were observed, e.g. some engineers' much lower sensitivity to maintenance costs (and disregarding their high risks) compared to non-technical people. Very low priorities of technical group for the sponsor's main objectives indicated some source of conflict in DM process, lack of communication or agreement on main objectives and signs of weak stakeholder engagement/management in initial and following project phases. Besides, ignoring or unwittingly missing some criteria revealed 'group-think' occurrence and/or (un)intentional biases towards the most desirable and technologically attractive option.

\section{Limitations}

The project entered another phase and the team dispersed by the end of the case so further reflections and extracting lessons learned by the actual team was not possible.

\section{Conclusions}


ISAHP Article: Application of the AHP in in analysis of decision making process in projects: case study of a major project decision - International Symposium of the Analytic Hierarchy Process 2016, London, U.K.

Use of the AHP to its full capacity rather than a peripheral method proved valuable for the analysis of DM process quality and not only its outcome. Possibility of analyzing the DM quality based on DMk groups by using numerical data was also very valuable.

\section{Key References}

Al-Harbi , K.M.A. (2001) 'Application of the AHP in project management', International Journal of Project Management, 19 (2001), pp.19-27.

Subramanian, N. \& Ramanathan, N. (2012) 'A review of applications of Analytic Hierarchy Process in operations management'. Int. Jr of Prod. Eco., 138, pp. 215-241.

von Solms, SH (2011) 'Validity of the AHP/ANP: Comparing Apples and Oranges'. International Journal of the Analytic Hierarchy Process, 3(1), pp. 2-27.

W. Saaty, R. (2007) 'Validating the Analytic Hierarchy/Network Processes'. ISAHPInternational Symposium on the Analytic hierarchy process. Chile, August 3-8, pp.1-27. 